\title{
Avaliação físico-química, microbiológica e reológica de bebida láctea e leite fermentado adicionados de probióticos
}

\section{Physico-chemical, microbiological and rheological evaluation of dairy beverage and fermented milk added of probiotics}

\author{
Thiago Meurer Cunha ${ }^{1}$; Fabiane Picinin de $\mathrm{Castro}^{1}$; Pedro Luiz Manique Barreto ${ }^{2}$; \\ Honório Domingos Benedet ${ }^{3}$; Elane Schwinden Prudêncio ${ }^{4 *}$
}

\section{Resumo}

\begin{abstract}
Bebida láctea (amostra 1), com $70 \%$ de leite e $30 \%$ de soro de queijo, e leite fermentado (amostra 2), com $100 \%$ de leite, adicionados de Lactobacillus acidophilus La-5, Bifidobacterium Bb-12 e Streptococcus thermophilus, foram avaliados quanto à composição físico-química, contagem de células viáveis de bactérias probióticas e medidas reológicas, nas temperaturas de $2,0 \pm 0,1^{\circ} \mathrm{C} ; 4,0 \pm 0,1^{\circ} \mathrm{C} ; 6,0 \pm 0,1^{\circ} \mathrm{C}$ e 8,0 $\pm 0,1^{\circ} \mathrm{C}$. A adição de soro resultou em uma bebida láctea com menores teores $(\mathrm{p}<0,05)$ de sólidos totais $(18,08 \pm 0,08 \% \mathrm{~m} / \mathrm{m})$, proteínas $(2,23 \pm 0,10 \% \mathrm{~m} / \mathrm{m})$, lipídios $(1,91 \pm 0,02 \% \mathrm{~m} / \mathrm{m})$ e valor calórico $(79,27 \pm$ $0,37 \mathrm{Kcal} / 100 \mathrm{~g}$ ), quando comparados aos teores apresentados no leite fermentado, respectivamente iguais a $19,44 \pm 0,02 \% \mathrm{~m} / \mathrm{m} ; 2,80 \pm 0,23 \% \mathrm{~m} / \mathrm{m} ; 3,03 \pm 0,08 \% \mathrm{~m} / \mathrm{m}$ e $90,47 \pm 0,53 \mathrm{Kcal} / 100 \mathrm{~g}$. Já, os teores de cinzas, carboidratos, acidez e $\mathrm{pH}$ da bebida láctea e do leite fermentado não diferiram $(\mathrm{p}>0,05)$. De acordo com a legislação brasileira, a bebida láctea e o leite fermentado foram considerados probióticos $\left(>10^{6} \mathrm{UFC} / \mathrm{mL}\right.$ ). As duas amostras (1 e 2) comportaram-se como fluidos pseudoplásticos, confirmando o comportamento não-Newtoniano e apresentaram tixotropia. Os valores para a energia de ativação foram iguais a 1,89 Kcal.mol ${ }^{-1}$, para a bebida láctea, e $1,84 \mathrm{Kcal}_{\mathrm{mol}}{ }^{-1}$, para o leite fermentado, indicando que a energia de ativação não foi influenciada pelo teor de soro empregado, bem como a temperatura também não teve influencia sobre a viscosidade aparente das amostras 1 e 2.

Palavras-chave: Soro de queijo, fermentação, composição centesimal, alimento funcional, viscosidade
\end{abstract}

\begin{abstract}
Lactic beverage (sample 1), with $70 \%$ of milk and $30 \%$ of cheese whey, and fermented milk (sample 2), with $100 \%$ of milk, added of Lactobacillus acidophilus La-5, Bifidobacterium Bb-12 and Streptococcus thermophilus, were evaluated about physico-chemical composition, enumeration of viable cells of probiotic bacteria and rheological measurements, in the temperatures of $2.0 \pm 0.1^{\circ} \mathrm{C} ; 4.0 \pm 0.1^{\circ} \mathrm{C} ; 6.0 \pm 0.1^{\circ} \mathrm{C}$ and $8.0 \pm$ $0.1^{\circ} \mathrm{C}$. The whey addition resulted in lactic beverage with lesser contents $(\mathrm{p}<0.05)$ of total solids $(18.08$ $\pm 0.08 \% \mathrm{~m} / \mathrm{m})$, proteins $(2,23 \pm 0.10 \% \mathrm{~m} / \mathrm{m})$, lipids $(1.91 \pm 0.02 \% \mathrm{~m} / \mathrm{m})$ and caloric value $(79.27 \pm 0.37 \mathrm{Kcal} /$
\end{abstract}

1 Farmacêutico(a)-Bioquímico(a), Mestrando(a) em Ciência dos Alimentos (CAL/CCA/UFSC).

2 Farmacêutico-Bioquímico, Doutor em Química (UFSC), Docente do Departamento de Ciência e Tecnologia de Alimentos do Centro de Ciências Agrárias da Universidade Federal de Santa Catarina.

3 Farmacêutico-Bioquímico, Doutor em Ciência de alimentos (FEAA/UNICAMP), Docente do Programa de Pós-Graduação em Ciências dos Alimentos do Departamento de Ciência e Tecnologia de Alimentos, do Centro de Ciências Agrárias da Universidade Federal de Santa Catarina.

4 Engenheira de Alimentos, Doutora em Ciência de Alimentos (CAL/CCA/UFSC), Docente do Departamento de Ciência e Tecnologia de Alimentos do Centro de Ciências Agrárias da Universidade Federal de Santa Catarina. E-mail: elane@cca.ufsc.br.

* Autor para correspondência 
$100 \mathrm{~g}$ ), when compared with those presented in fermented milk, respectively. While, the contents of ashes, carbohydrates, the acidity and $\mathrm{pH}$ of the lactic beverage and fermented milk weren't different ( $\mathrm{p}$ $>0.05$ ). According to Brazilian legislation the lactic beverage and fermented milk were considered probiotic $\left(>10^{6} \mathrm{CFU} / \mathrm{mL}\right)$. The two samples ( 1 and 2$)$ had behaved as pseudoplastic fluids, confirming the nonNewtonian behavior and had presented thixotropy. The values for the activation energy were equal to $1.89 \mathrm{Kcal}_{\mathrm{mol}}{ }^{-1}$, for the lactic beverage, and $1.84 \mathrm{Kcal}_{\mathrm{mol}}{ }^{-1}$, for the fermented milk, indicating that the activation energy was not influenced by the amount of whey used, as well as the temperature also did not influence on the apparent viscosity of samples 1 and 2.

Key words: Whey, fermentation, centesimal composition, functional food, viscosity

\section{Introdução}

Os probióticos são descritos como microrganismos vivos que quando administrados em quantidade adequada conferem benefícios aos seus consumidores (FOOD AND AGRICULTURE ORGANIZATION OF THE UNITED NATIONS - FAO; WORLD HEALTH ORGANIZATION WHO, 2001). A incorporação de microrganismos probióticos como adjuntos dietéticos em diferentes produtos lácteos tem reforçado suas propriedades funcionais, resultando em aumento no consumo (KRISTO; BILIADERIS; TZANETAKIS, 2003), além de excelentes características sensoriais (VINDEROLA; BAILO; REINHEIMER, 2000). Em derivados lácteos as bactérias probióticas mais utilizadas são Lactobacillus acidophilus e Bifidobacterium (FIORAMONTI; THEODOROU; BUENO, 2003; GOMES; MALCATA, 1999; LOURENS-HATTINGH; VILJOEN, 2001). Estes microrganismos apresentam diversas características em comum como, por exemplo, são seguros ou Generally Regarded As Safe (GRAS), apresentam capacidade de adesão à mucosa intestinal e são tolerantes aos ácidos e a bile (DUNNE et al., 2001).

O soro de queijo, denominado doce $(\mathrm{pH}$ entre $6 \mathrm{e}$ 7), além de ser considerado um produto secundário da indústria queijeira, é resultante do processo de coagulação enzimática do leite (RODRIGUES; TEIXEIRA; OLIVEIRA, 2006). Este produto secundário além de representar cerca de 85 a $95 \%$ do volume inicial de leite empregado na fabricação de um queijo, contém aproximadamente $55 \%$ do total de nutrientes do leite (SISO, 1996), sendo desta forma considerado fonte de lactose, cálcio, proteínas e vitaminas hidrossolúveis (GONZÁLEZ-MARTÍNEZ et al., 2002). Atualmente o soro de queijo é reconhecido pelas suas propriedades nutricionais e funcionais, não somente pelo alto valor biológico de suas proteínas, mas também pelo teor de aminoácidos sulfurados presentes nas proteínas do soro (SINHA et al., 2007).

A conversão do soro líquido em bebidas lácteas fermentadas ou não, seria uma das mais atrativas opções para as indústrias devido à simplicidade do processo; a possibilidade de uso dos equipamentos já existentes na usina de beneficiamento de leite (ALMEIDA; BONASSI; ROÇA, 2000); a substituição do uso de soro em pó, reduzindo custos (THAMER; PENNA, 2005); além da redução de problemas relativos ao seu descarte (PINTADO; MACEDO; MALEATA, 2001).

Lerayer et al. (2002) definem bebida láctea como um tipo de leite fermentado que vem se destacando como "substituto" do iogurte, podendo ser utilizados leite ou leite reconstituído e/ou derivados de leite, incluindo neste caso o soro de queijo, todos reconstituídos ou não. Porém, a proporção leite e soro ainda não é bem definida (PENNA; SIVIERI; OLIVEIRA, 2001).

O uso de diferentes tipos de cultivos bacterianos iniciadores (AFONSO; MAIA, 1999; LIN et al., 2006), a adição de soro (LUCEY; MUNRO; SINGH, 1999), a composição do leite (AFONSO; MAIA, 1999), o processamento (AICHINGER et al., 2003), incluindo as etapas pós-fermentação, como por exemplo, a quebra do coágulo e a temperatura de armazenagem (AFONSO; MAIA, 1999; KEOGH; O'KENNEDY, 1998), poderiam modificar as propriedades químicas, microbiológicas e reológicas 
de leites fermentados. Destas propriedades as características reológicas são essenciais para a aceitabilidade, o manuseio de derivados lácteos, o desenho e a forma de operação dos equipamentos industriais (AWADHWAL; SING, 1985).

No estudo da reologia de produtos lácteos, o modelo da lei da Potência é freqüentemente aplicado para descrever as propriedades de fluxo de iogurtes (ABU-JDAYIL; MOHAMEED, 2002), iogurtes elaborados a partir de leite e soro concentrados por ultrafiltração (MAGENIS et al., 2006) e bebidas lácteas (PENNA; SIVIERI; OLIVEIRA, 2001). Este modelo foi utilizado por Abu-Jdayil e Mohameed (2002) para determinar os índices de consistência e de comportamento de fluxo de iogurtes utilizando as curvas de viscosidade através da Equação 1.

$$
\eta=\kappa(\gamma)^{\mathrm{n}-1} \quad \text { Equação } 1
$$

onde $\eta$ é a viscosidade aparente, $\kappa$ o índice de consistência, $\gamma$ a taxa de deformação e n o índice de comportamento de fluxo, que é menor do que 1 para fluidos com comportamento pseudoplástico.

As medidas de viscosidade sempre resultam primeiramente em uma curva de fluxo, onde os resultados são, então, rearranjados matematicamente para que seja possível traçar a curva de viscosidade correspondente (SCHRAMM, 2006). Porém, o modelo da lei da Potência não considera os efeitos de temperatura, sendo necessária para quantificar o efeito da temperatura na viscosidade aparente de fluidos alimentares, a Equação de Arrhenius (Equação 2), que leva em conta a energia de ativação (AFONSO et al., 2003; BARRETO et al., 2003; VELEZ-RUIZ; BARBOSA-CÁNOVAS, 1998).

$$
\eta=\eta_{0} \exp \left(\mathrm{E}_{\mathrm{a}} / \mathrm{RT}\right) \quad \text { Equação } 2
$$

onde $\eta$ é a viscosidade aparente ( $\mathrm{mPa} \mathrm{s}), \eta_{0}$ uma constante ( $\mathrm{mPa} \mathrm{s}$ ), $\mathrm{E}_{\mathrm{a}}$ a energia de ativação $\left(\mathrm{cal}^{\mathrm{mol}} \mathrm{m}^{-1}\right)$, $\mathrm{R}$ a constante molar dos gases $\left(1,987 \mathrm{cal} \cdot \mathrm{K}^{-1} \cdot \mathrm{mol}^{-1}\right) \mathrm{e}$ $\mathrm{T}$ a temperatura absoluta $(\mathrm{K})$.
O objetivo deste trabalho foi avaliar a composição físico-química, a contagem de células viáveis de bactérias probióticas e as medidas reológicas de bebida láctea fermentada elaborada com $70 \%$ de leite e $30 \%$ de soro de queijo e leite fermentado elaborado com $100 \%$ de leite, armazenadas a $5 \pm 1{ }^{\circ} \mathrm{C}$.

\section{Material e métodos}

\section{Material}

Leite pasteurizado e padronizado ( $3 \%$ de gordura), soro de queijo obtido da fabricação de queijo tipo Minas Frescal, cultura lática termofílica contendo Streptococcus salivarius subesp. thermophilus, Lactobacillus acidophilus (LA-5) e Bifidobacterium (Bb-12) (ABT-4 ${ }^{\circledR}$, Chr. Hansen, Hønsholm, Dinamarca) e sacarose foram empregados.

Todos os reagentes utilizados foram de grau analítico (p.a.), enquanto o meio de cultura foi o MRS (DE MAN; ROGOSA; SHARPE) da Merck ${ }^{\circledR}$ (KGaA, Darmstadt, Alemanha).

Elaboração da bebida láctea e do leite fermentado

A elaboração da bebida láctea, obtida a partir do leite e do soro de queijo, e do leite fermentado foi baseada na metodologia descrita por Almeida, Bonassi e Roça (2001) (com modificações) (Figura 1). O leite adicionado de sacarose $(10 \mathrm{~g} / 100 \mathrm{~g}$ do volume de leite ou da mistura de leite e soro), foi pasteurizado a $95^{\circ} \mathrm{C}$ por 5 minutos, enquanto o soro foi aquecido a $65^{\circ} \mathrm{C}$ por 30 minutos. Ambos foram submetidos ao abaixamento da temperatura para 40 ${ }^{\circ} \mathrm{C}$ e utilizados na elaboração das seguintes amostras: bebida láctea elaborada com $70 \%$ de leite e $30 \%$ de soro de queijo (amostra 1) e leite fermentado elaborado com $100 \%$ de leite (amostra 2), que foram adicionadas da cultura lática (1\%) e submetidas a fermentação a $40{ }^{\circ} \mathrm{C}$. A fermentação das amostras foi conduzida até $\mathrm{pH}$ em torno de 4,6 , sendo resfriadas a $4{ }^{\circ} \mathrm{C}$, batidas lentamente e armazenadas a $5 \pm 1{ }^{\circ} \mathrm{C}$, até a realização das análises. $\mathrm{O}$ experimento foi realizado em triplicata. 


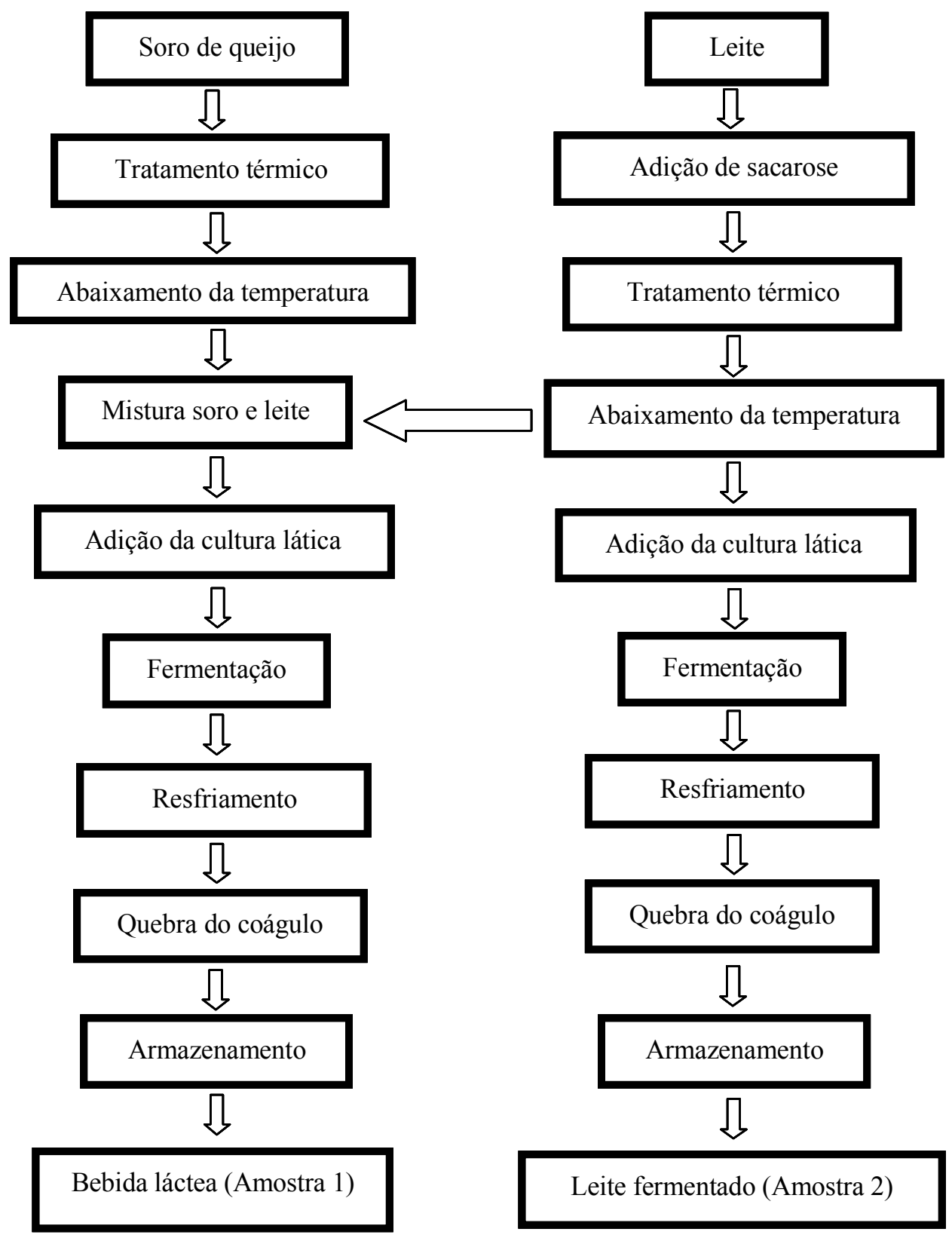

Figura 1. Fluxograma de elaboração da bebida láctea (amostra 1 , com $70 \%$ de leite e $30 \%$ de soro de queijo) e do leite fermentado (amostra 2, com 100 \% de leite). Fonte: Almeida, Bonassi e Roça (2001) (com modificações).

\section{Análise físico-química}

O leite, o soro e as amostras 1 e 2 foram submetidos as seguintes análises físico-químicas: umidade $(\% \mathrm{~m} / \mathrm{m})$, Sólidos Totais (ST) $(\% \mathrm{~m} / \mathrm{m})$, proteínas $(\% \mathrm{~m} / \mathrm{m})$, cinzas $(\% \mathrm{~m} / \mathrm{m})$, lipídeos $(\% \mathrm{~m} /$ m) (ASSOCIATION OF OFFICIAL ANALYTICAL CHEMISTS - AOAC, 2005) e acidez (\% ácido lático e ${ }^{\circ} \mathrm{D}$ ) (INSTITUTO
ADOLFO LUTZ - IAL, 2005). Os valores de carboidratos totais foram obtidos por diferença. As medidas dos valores de $\mathrm{pH}$ foram realizadas utilizando pH metro (MP220, Metler-Toledo, Greinfensee, Suíça). Todas as análises foram realizadas em triplicata. Os valores calóricos das amostras 1 e 2 foram calculados pelos fatores de Atwater, proteínas igual a 4,0 (Kcal/g); carboidratos 4,0 (Kcal/g) e lipídeos 9,0 (Kcal/g) (DE ANGELIS, 1977). 


\section{Análise microbiológica}

Antes e após a fermentação, as amostras 1 e 2 foram avaliadas quanto à contagem de células viáveis de Lactobacillus acidophilus LA-5 e Bifidobacterium Bb-12. Foi empregado o meio de cultura MRS modificado com a adição de $0,15 \%$ $(\mathrm{m} / \mathrm{v})$ de Bile (MRS-Bile) para a contagem de $L$. acidophilus e o meio de cultura MRS modificado com a adição de $0,2 \%(\mathrm{~m} / \mathrm{v})$ de lítio e $0,3 \%(\mathrm{~m} / \mathrm{v})$ de propionato de sódio (MRS-LP) para a contagem de bifidobactéria. Foram realizadas diluições seriadas das amostras, plaqueadas em triplicata na superfície dos meios utilizando alíquotas de $0,1 \mathrm{~mL}$. As placas com MRS-Bile foram incubadas sob aerobiose e as placas com MRS-LP sob anaerobiose (AnaeroGen ${ }^{\circledR}$ ) a $37{ }^{\circ} \mathrm{C}$ por 72 horas (VINDEROLA; REINHEIMER, 2000). Após este período foram realizadas as contagens das colônias de $L$. acidophilus e de bifidobactéria.

\section{Medidas reológicas}

As medidas reológicas das amostras 1 e 2 foram determinadas em um reômetro rotacional (Brookfield Engineering Laboratories model DVIII Ultra, Stoughton, MA, USA) com cilindros concêntricos, spindle SC4-21 e coletadas através do software Rheocalc $^{\circledR} 32$ (versão 2.5). A taxa de deformação aumentou linearmente de 1,86 a $38,13 \mathrm{~s}^{-1}$ nos primeiros 40 minutos (curva ascendente) e retornou para 1,86 $\mathrm{s}^{-1}$ nos 40 minutos seguintes (curva descendente), sob temperaturas controladas de $2,0 \pm 0,1^{\circ} \mathrm{C} ; 4,0 \pm$ $0,1{ }^{\circ} \mathrm{C} ; 6,0 \pm 0,1{ }^{\circ} \mathrm{C}$ e $8,0 \pm 0,1{ }^{\circ} \mathrm{C}$, através da circulação da água em um banho (Tecnal, modelo TE-184, Piracicaba, SP, BR) com controle de temperatura. A velocidade rotacional aumentou de 2 a $41 \mathrm{rpm}$, aumentando $1 \mathrm{rpm}$ a cada minuto. Todas as medidas foram realizadas em triplicata.

As curvas de fluxo foram descritas pelo modelo da Lei da Potência. Os valores de viscosidade na curva de viscosidade/taxa de deformação na taxa de deformação de $10 \mathrm{~s}^{-1}$ foram determinados como a viscosidade aparente das amostras (YANES; DURÁN; COSTELL, 2002).

Os valores da energia de ativação foram determinados a partir da viscosidade aparente nas diferentes temperaturas $\left(2,0 \pm 0,1{ }^{\circ} \mathrm{C} ; 4,0 \pm 0,1{ }^{\circ} \mathrm{C}\right.$; $6,0 \pm 0,1^{\circ} \mathrm{C}$ e $8,0 \pm 0,1{ }^{\circ} \mathrm{C}$ ) mediante a equação de Arrhenius (MULLINEUX; SIMMONS, 2007; SILVA; GUIMARÃES; GASPARETTO, 2005), a uma taxa de deformação também igual a $10 \mathrm{~s}^{-1}$.

\section{Análise estatística}

As médias, o desvio padrão e a análise de variância (5\% de significância) dos dados foram obtidos através do software STATISTICA versão 6.0 (STATSOFT INC., 2001).

\section{Resultados e Discussão}

Análise físico-química

Os resultados médios das composições físicoquímicas do leite, do soro de queijo e das amostras 1 e 2 estão apresentados na Tabela 1. Pode-se verificar que a adição de soro resultou em um produto com menores teores $(\mathrm{p}<0,05)$ de sólidos totais $(\mathrm{ST})$, proteínas e lipídeos. Na amostra 1 os valores encontrados para ST foram próximos aos obtidos por Penna, Sivieri e Oliveira (2001) (19,01 a 21,71\%), para bebidas lácteas comerciais, enquanto os teores protéicos foram similares aos encontrados por Almeida, Bonassi e Roça (2001) (1,94 a 2,14 \%), que elaboraram bebidas com teores de soro entre 30 e $50 \%$. Os teores lipídicos também encontrados por Penna, Sivieri e Oliveira (2001) (1,1 a 1,8\%) e Almeida, Bonassi e Roça (2001) (1,59 a 2,01 \%) foram semelhantes aos resultados obtidos para a amostra 1. Enquanto para a amostra 2 o teor de ST ficou próximo dos limites encontrados por Oliveira e Damin (2003) (19,50 a 22,50 \%), que elaboraram iogurtes probióticos adicionados de sacarose, e aos determinados por Musaiger et al. (1998) (3,00 \% e $2,40 \%$ ), para os teores protéico e lipídico de iogurtes obtidos a partir do leite de vaca. 
Tabela 1. Médias (desvio padrão) da composição físico-química do leite, soro de queijo, bebida láctea (amostra 1) e leite fermentado (amostra 2).

\begin{tabular}{lcccc}
\hline & LEITE & SORO & AMOSTRA 1 & AMOSTRA 2 \\
\hline Umidade $(\% \mathrm{~m} / \mathrm{m})$ & $88,16(0,06)$ & $93,90(0,00)$ & $81,91(0,08)^{\mathrm{b}}$ & $80,56(0,02)^{\mathrm{a}}$ \\
ST $(\% \mathrm{~m} / \mathrm{m})$ & $11,84(0,06)$ & $6,10(0,00)$ & $18,08(0,08)^{\mathrm{b}}$ & $19,44(0,02)^{\mathrm{a}}$ \\
Proteínas $(\% \mathrm{~m} / \mathrm{m})$ & $3,14(0,02)$ & $0,66(0,04)$ & $2,23(0,10)^{\mathrm{b}}$ & $2,80(0,23)^{\mathrm{a}}$ \\
Cinzas $(\% \mathrm{~m} / \mathrm{m})$ & $0,80(0,00)$ & $0,53(0,00)$ & $0,65(0,02)^{\mathrm{a}}$ & $0,60(0,03)^{\mathrm{a}}$ \\
Lipídeos $(\% \mathrm{~m} / \mathrm{m})$ & $3,00(0,00)$ & $0,16(0,00)$ & $1,91(0,02)^{\mathrm{b}}$ & $3,03(0,08)^{\mathrm{a}}$ \\
Carboidratos totais $(\% \mathrm{~m} / \mathrm{m})$ & $4,90(0,00)$ & $4,74(0,04)$ & $13,29(0,04)^{\mathrm{a}}$ & $13,00(0,27)^{\mathrm{a}}$ \\
Acidez $(\%$ ácido lático) & $0,17(0,01)$ & $0,11(0,01)$ & $0,72(0,00)^{\mathrm{a}}$ & $0,70(0,01)^{\mathrm{a}}$ \\
Acidez $\left({ }^{\circ} \mathrm{D}\right)$ & $17,33(1,15)$ & $10,66(0,58)$ & $72,33(1,53)^{\mathrm{a}}$ & $70,33(0,58)^{\mathrm{a}}$ \\
pH & $6,69(0,02)$ & $6,23(0,04)$ & $4,53(0,08)^{\mathrm{a}}$ & $4,60(0,00)^{\mathrm{a}}$ \\
Valor calórico $(\mathrm{Kcal} / 100 \mathrm{~g})$ & $59,13(0,01)$ & $23,04(0,03)$ & $79,27(0,37)^{\mathrm{a}}$ & $90,47(0,53)^{\mathrm{b}}$ \\
\hline
\end{tabular}

Médias com letras iguais na mesma linha não diferiram entre si $(\mathrm{p}>0.05)$.

AMOSTRA 1: Bebida láctea com $70 \%$ de leite e $30 \%$ de soro de queijo.

AMOSTRA 2: Leite fermentado com $100 \%$ de leite.

ST: Sólidos Totais

Nas amostras avaliadas os teores de cinzas e carboidratos, assim como os valores para a acidez (\% ácido lático e $\left.{ }^{\circ} \mathrm{D}\right)$ e $\mathrm{pH}$ não apresentaram diferenças $(p>0,05)$. Resultados iguais foram encontrados por Yazici e Akgun (2004) em iogurtes elaborados a partir de leites com 0,5 e 2,0\% de lipídeos, cujos teores de cinzas ficaram em torno de $0,66 \%$. Os teores de carboidratos totais das amostras 1 e 2 foram maiores do que os encontrados na literatura para iogurtes de leite de vaca $(5,4$ e 6,6 $\%$ ), porém a adição de sacarose justificaria o aumento nos valores determinados. Em amostras de iogurtes comerciais, Moreira et al. (1999) encontraram limites para a acidez de 0,70 e 1,20\% de ácido lático, enquanto Donkor et al. (2006), Moreira et al. (1999), Penna, Sivieri e Oliveira (2001) e obtiveram valores para o $\mathrm{pH}$ entre 3,86 - 4,08, 3,76 - 4,39 e 4,45 - 4,60, para bebidas lácteas comerciais, iogurtes comerciais e iogurtes probióticos, respectivamente. Kailasapathy (2006) afirma que leites fermentados comerciais tendem a apresentar maiores valores de acidez com o armazenamento, devido a atividade da âgalactosidase em temperaturas entre 0 e $5{ }^{\circ} \mathrm{C}$, resultando na pós-acidificação do produto.

A substituição de parte da quantidade de leite por soro contribuiu também para obtenção de um produto com menor valor calórico, porém os valores

encontrados para as amostras 1 e 2 ficaram dentro do verificado por Musaiger et al. (1998) (55 a 106 $\mathrm{Kcal} / 100 \mathrm{~g}$ ) em iogurtes comerciais.

\section{Análise microbiológica}

Os resultados da contagem de células viáveis probióticas realizadas antes e após o processo de fermentação, das amostras 1 e 2 (Figura 2), demonstraram que a adição inicial de bactérias probióticas foi suficiente para a obtenção de produtos probióticos, pois foram encontrados valores maiores do que $10^{6} \mathrm{UFC} / \mathrm{mL}$. De acordo com MartinezVillaluenga et al. (2006) este seria o menor limite estipulado pelo International Standard IDF/FIL para um alimento ser declarado probiótico. Resultados semelhantes foram obtidos para leites fermentados (AWAISHEH; HADDADIN; ROBINSON, 2005; ELGAWAD et al., 2005; PINTO et al., 2006), iogurte de soja (EL-GAWAD et al., 2005), iogurte de leite de ovelha (BONCZAR; WSZOLEK; SIUTA, 2002), iogurte de leite de cabra (FARNSWORTH et al., 2006; GÜLER-AKIN; AKIN, 2007) e leite de búfala fermentado (FARIA; BENEDET; GUERROUE, 2006). Porém, Kastner et al. (2006) recomendam que mais estudos sejam realizados a fim de otimizar a sobrevivência de bactérias probióticas. 


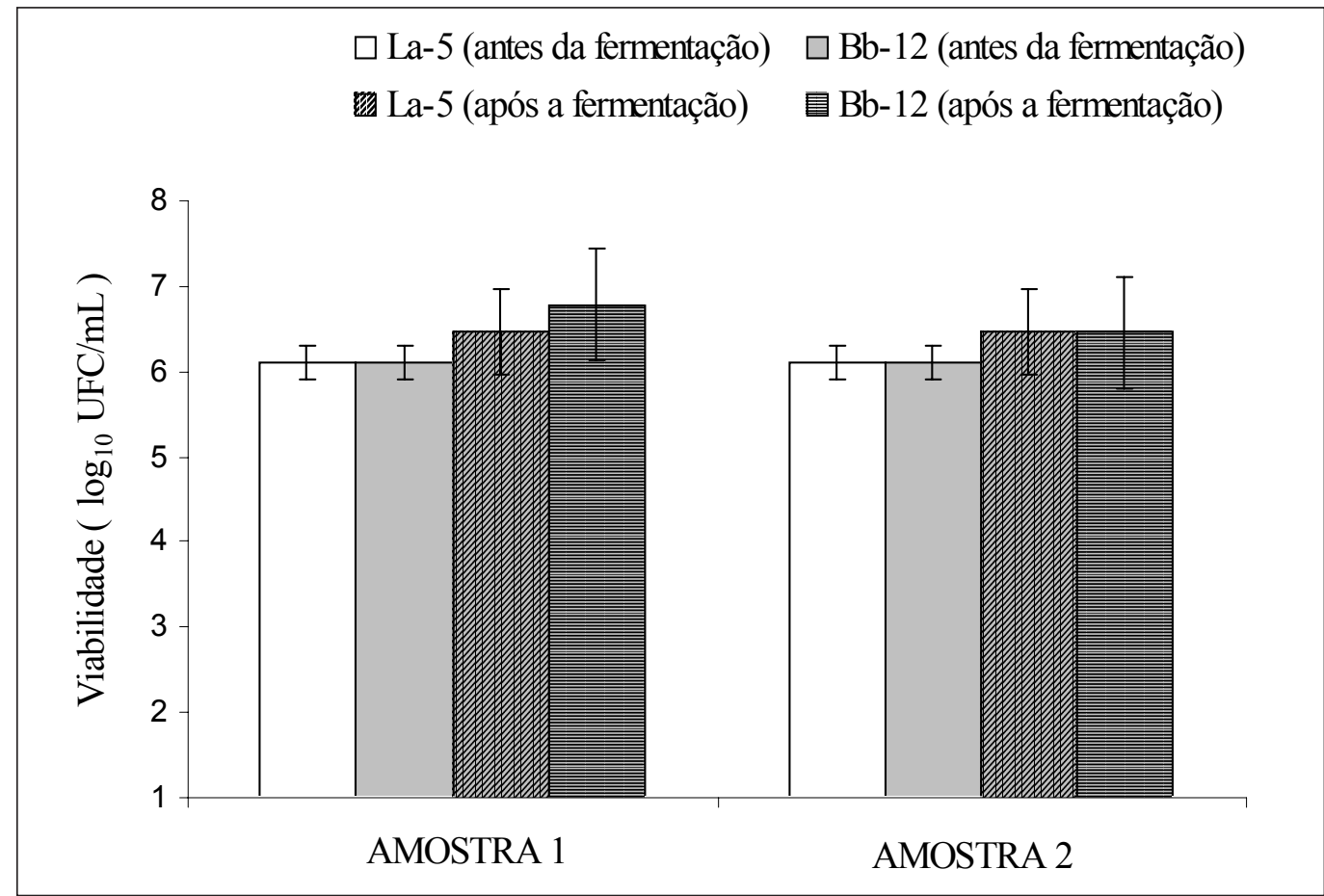

Figura 2. Resultados referentes à contagem total de células viáveis das bactérias probióticas avaliadas (Lactobacillus acidophilus LA-5 e Bifidobacterium Bb-12, $\log _{10}$ da unidade formadora de colônia-UFC/mL) na amostra 1 , com 70 \% de leite e $30 \%$ de soro e queijo, e na amostra 2, com $100 \%$ de leite, antes e após a etapa de fermentação.

Antes e após o período de fermentação também não foram observadas diferenças entre a contagem de células viáveis probióticas nas amostras 1 e 2 . Este comportamento foi similar ao encontrado por Martín-Diana et al. (2003) para leites fermentados com bifidobactérias. Segundo estes autores, é recomendado que a quantidade de microrganismos inoculados seja a mesma desejada no produto final, devido ao baixo desenvolvimento das bifidobactérias no leite. Além da quantidade inoculada, a viabilidade de bactérias probióticas em iogurtes pode também ser dependente da cultura utilizada, da interação entre outras espécies presentes, da presença de oxigênio dissolvido, do tipo de matéria-prima empregada (MARAGKOUDAKIS et al., 2006; SHAH, 2000), como por exemplo, soro em pó (KAILASAPATHY; SUPRIADI, 1996), entre outros. Portanto, a manutenção da contagem de células viáveis probióticas no produto fermentado poderia ter sido influenciada pelo uso da cultura mista adicionada. Moreira, Abraham e De Antoni (2000) observaram um efeito sinérgico na associação de bactérias em derivados lácteos. Quanto à manutenção da contagem de células viáveis probióticas, resultados similares foram também encontrados por Martínez-Villaluenga et al. (2006) em leites fermentados contendo cultura mista de L. acidophilus, Bifidobacterium e $S$. thermophilus. O emprego de S. thermophilus segundo Lin et al. (2006) diminui o teor de oxigênio no meio, contribuindo para a estabilidade e manutenção das bifidobactérias.

\section{Medidas reológicas}

A viscosidade aparente das amostras (1 e 2), nas diferentes temperaturas testadas, diminuiu com o aumento da taxa de deformação, indicando comportamento de fluido não-Newtoniano (Figura 3 a, b). Estes resultados estão de acordo com estudos realizados em bebidas lácteas comerciais, iogurte batido e iogurte adicionado de soro concentrado por ultrafiltração, realizados por Penna, Sivieri e Oliveira (2001), O’Donnell e Butler (2002) e Magenis et al. (2006) respectivamente. Nas temperaturas avaliadas, 
a diminuição da viscosidade aparente das amostras, com o aumento da taxa de cisalhamento (Figura 3 a e b), pode ter ocorrido, segundo Horne (1998) e Lucey (2002), devido à destruição das fracas ligações físicas existentes e à diminuição da energia de interação entre as moléculas. Horne (1998) define a energia de interação das moléculas como o somatório da repulsão eletrostática e da interação hidrofóbica, portanto, a queda na viscosidade aparente das amostras com o aumento da taxa de deformação poderia ser resultado da destruição destas interações. De acordo com Magenis et al. (2006) isto caracterizaria o comportamento pseudoplástico de leites fermentados, com e sem o uso de soro de queijo. Shaker, Jumah e Abu-Jdayil (2000) e Abu-Jdayil e Mohameed (2002) também observaram um comportamento pseudoplástico quando a viscosidade aparente diminuiu com o aumento da taxa de deformação em iogurtes naturais e em labneh (tipo de leite fermentado concentrado e dessorado), respectivamente.

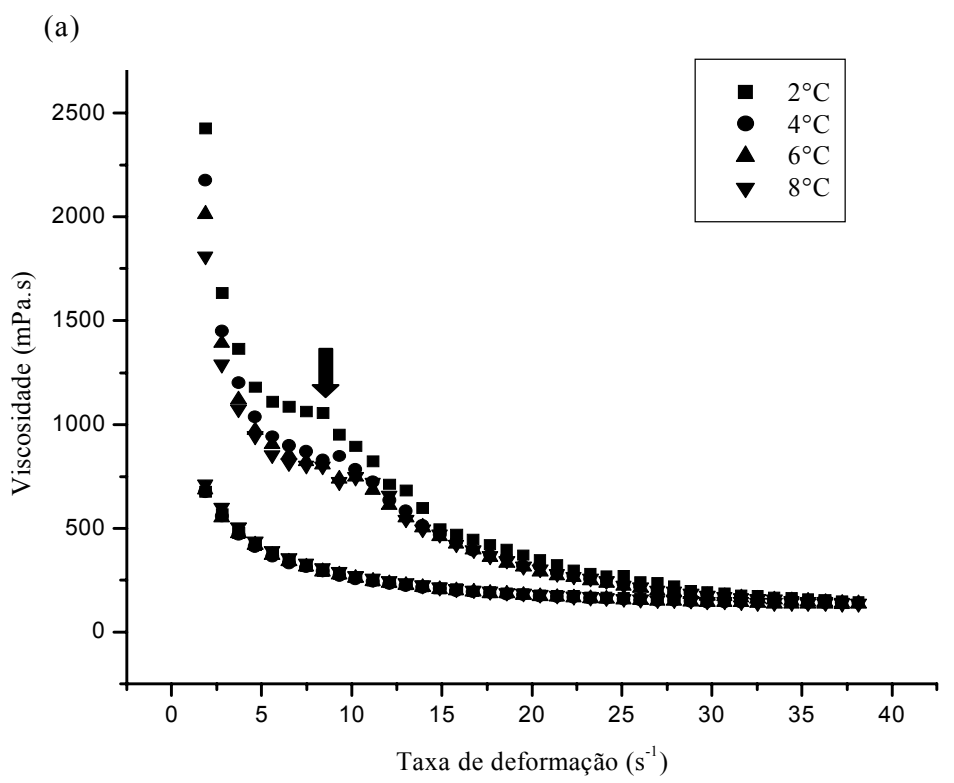

(b)

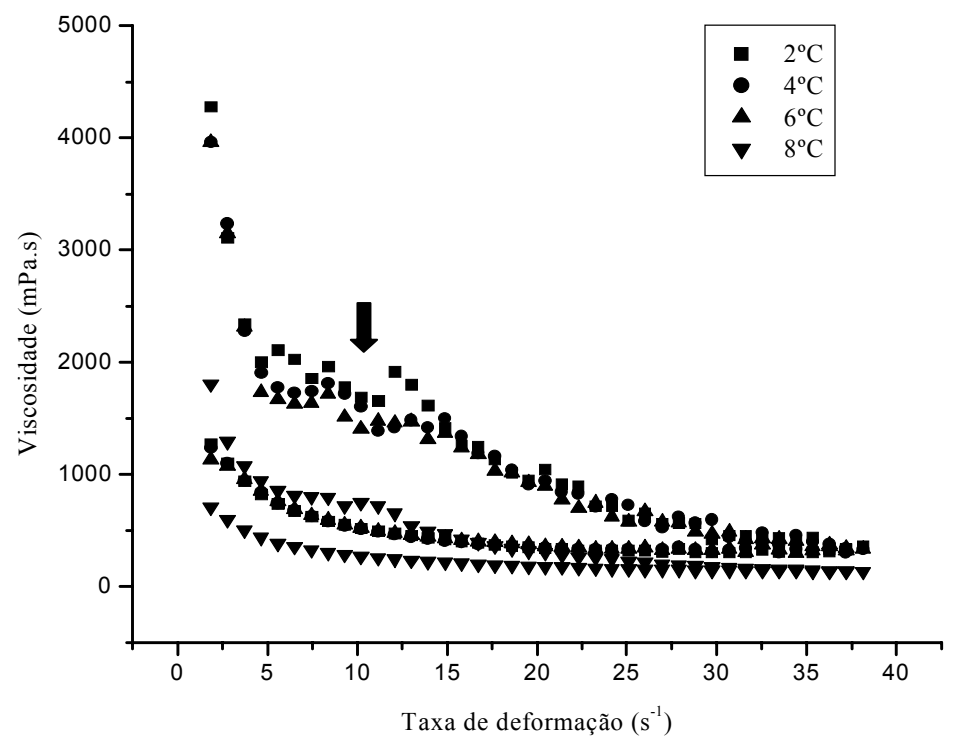

Figura 3. (a) Relação da viscosidade aparente $\mathrm{x}$ taxa de deformação da bebida láctea, com $70 \%$ de leite e $30 \%$ de soro de queijo (amostra 1) e (b) leite fermentado, com $100 \%$ de leite (amostra 2), em diferente temperaturas. 
Na Figura 3 (a, b) observa-se na curva ascendente, em todas as temperaturas avaliadas, a formação de picos. O mesmo comportamento foi observado por Lucey e Singh (1998). Sodini et al. (2005) relatam que depois da agregação/gelatinização das proteínas do soro, outros rearranjos na rede do gel são observados, como por exemplo, a associação das partículas de caseína à medida que elas atingem seu ponto isoelétrico $(\mathrm{pH}=4,6)$. Estes autores afirmam que tais rearranjos podem levar a uma etapa de transição, onde se observa a agregação das proteínas do soro, inicialmente desnaturadas (em $\mathrm{pH}$ $=5,2$ ), com as partículas de caseínas associadas em um $\mathrm{pH}$ igual a 4,6. Esta transição resultaria um estresse local na rede do gel, levando a defeitos, ou seja, a formação de grânulos, que seriam então os prováveis responsáveis pelo aparecimento dos picos nas curvas ascendentes.

Quando as amostras foram submetidas ao aumento e posterior diminuição da tensão de cisalhamento verificou-se mudanças no comportamento reológico (Figura $3 \mathrm{a}, \mathrm{b}$ ), indicando a presença de tixotropia. Conforme Penna, Sivieri e Oliveira (2001) isto ocorreria devido à degradação da estrutura do produto. A tixotropia, segundo Schramm (2006), seria causada pela quebra da estrutura de uma dispersão sobre uma tensão. Portanto, partículas frágeis ou ligações fracas entre as partículas envolvidas podem ser quebradas quando submetidas a esta tensão (SHOEMAKER; FIGONI, 1984). Teo, Munro e Singh (2000) afirmam que a tixotropia de soluções de proteínas de soro é caracterizada pela quebra das ligações dissulfídicas e de Van der Waals, e pelas interações iônicas e hidrofóbicas existentes entre as partículas de proteínas. Estes resultados estão de acordo com os obtidos por Magenis et al. (2006) que observaram também comportamento dependente do tempo e irreversível em iogurte e iogurte adicionado de soro concentrado por ultrafiltração.
Os parâmetros reológicos das amostras descritos pelo modelo da lei da potência, nas temperaturas analisadas, estão na Tabela 2. Os coeficientes de correlação para o modelo foram iguais ou maiores que 0,97 e 0,94 para as amostras 1 e 2, respectivamente. Com isto observa-se que o modelo da lei da potência foi adequadamente empregado, ou seja, conseguiu descrever o comportamento reológico da bebida láctea fermentada e do leite fermentado, ambos probióticos. Comportamento semelhante foi obtido por Penna, Sivieri e Oliveira (2001) para bebidas lácteas comerciais a 5 e $25^{\circ} \mathrm{C}$. A viscosidade aparente das amostras nas temperaturas avaliadas $\left(2,0 \pm 0,1^{\circ} \mathrm{C} ; 4,0 \pm 0,1^{\circ} \mathrm{C} ; 6,0 \pm 0,1^{\circ} \mathrm{C}\right.$ e $\left.8,0 \pm 0,1^{\circ} \mathrm{C}\right)$ também diminuiu com a adição de soro. Resultados similares foram obtidos por Sodini et al. (2005) para iogurtes suplementados com hidrolisado protéico de leite. Estes autores afirmam que tempos de fermentações prolongados, como os necessários para a obtenção de leites fermentados com bactérias probióticas (MARTÍN-DIANA et al., 2003), permitem um grande número de ligações durante o primeiro estágio de coagulação, onde ocorre a agregação das proteínas do soro. Tal fato poderia gerar um grande estresse na rede durante o segundo estágio de coagulação, fase de agregação das caseínas, resultando desta forma em menores quantidades de caseínas agregadas e conseqüentemente em um gel menos firme e viscoso. Martín-Diana et al. (2003) afirmam que o teor de $\mathrm{ST}$, bem como o de proteínas também pode influenciar na viscosidade de um produto. Isto é confirmado quando se observa o resultado obtido para estes teores (Tabela 1), onde a amostra 2 (leite fermentado), mais viscosa, contém maiores teores de ST e proteínas do que a amostra 1 (bebida láctea fermentada). Este comportamento foi igual ao determinado por Martín-Diana et al. (2003) que verificaram maiores valores para a viscosidade de leite de cabra suplementado com $5 \%$ de Concentrado Protéico de Soro (CPS). 
Tabela 2. Parâmetros reológicos obtidos utilizando-se o modelo da Lei da Potência $\left(\eta=\kappa(\gamma)^{n-1}\right)$ e a viscosidade aparente da bebida láctea (amostra 1) e leite fermentado (amostra 2), em diferentes temperaturas.

\begin{tabular}{|c|c|c|c|c|}
\hline Amostras & $\begin{array}{c}\text { Índice de } \\
\text { consistência } \\
\left(\mathrm{K}, \text { Pa.s }^{-1}\right)\end{array}$ & $\begin{array}{c}\text { Índice de } \\
\text { comportamento de } \\
\text { fluxo }(n)\end{array}$ & $\begin{array}{l}\text { Viscosidade } \\
\text { aparente } \\
\left(\text { Pa.s }^{-1}\right)^{*}\end{array}$ & $\mathbf{R}$ \\
\hline \multicolumn{5}{|l|}{ Amostra 1} \\
\hline \multicolumn{5}{|c|}{ Curva ascendente } \\
\hline $2{ }^{\circ} \mathrm{C}$ & 6,70 & 0,00 & 660,48 & 0,97 \\
\hline $4^{\circ} \mathrm{C}$ & 5,48 & 0,02 & 581,02 & 0,97 \\
\hline $6^{\circ} \mathrm{C}$ & 4,98 & 0,05 & 556,29 & 0,98 \\
\hline $8^{\circ} \mathrm{C}$ & 4,58 & 0,08 & 549,98 & 0,97 \\
\hline \multicolumn{5}{|c|}{ Curva descendente } \\
\hline $2{ }^{\circ} \mathrm{C}$ & 0,94 & 0,46 & - & 0,99 \\
\hline $4^{\circ} \mathrm{C}$ & 0,92 & 0,46 & - & 0,99 \\
\hline $6^{\circ} \mathrm{C}$ & 0,95 & 0,44 & - & 0,99 \\
\hline $8^{\circ} \mathrm{C}$ & 1,03 & 0,43 & - & 0,99 \\
\hline \multicolumn{5}{|l|}{ Amostra 2} \\
\hline \multicolumn{5}{|c|}{ Curva ascendente } \\
\hline $2{ }^{\circ} \mathrm{C}$ & 10,10 & 0,15 & 1442,57 & 0,94 \\
\hline $4^{\circ} \mathrm{C}$ & 8,59 & 0,20 & 1370,64 & 0,94 \\
\hline $6^{\circ} \mathrm{C}$ & 8,25 & 0,20 & 1307,87 & 0,95 \\
\hline $8^{\circ} \mathrm{C}$ & 7,20 & 0,21 & 1179,64 & 0,94 \\
\hline \multicolumn{5}{|c|}{ Curva descendente } \\
\hline $2^{\circ} \mathrm{C}$ & 1,67 & 0,50 & - & 0,98 \\
\hline $4^{\circ} \mathrm{C}$ & 1,61 & 0,52 & - & 0,97 \\
\hline $6^{\circ} \mathrm{C}$ & 1,58 & 0,54 & - & 0,98 \\
\hline $8^{\circ} \mathrm{C}$ & 1,50 & 0,53 & - & 0,98 \\
\hline
\end{tabular}

Amostra 1: bebida láctea com $70 \%$ de leite e $30 \%$ de soro. Amostra 2: leite fermentado com $100 \%$ de leite.

*Viscosidade aparente à uma taxa de deformação de $10 \mathrm{~s}^{-1}$.

Assim como a viscosidade aparente, foi observado nas amostras 1 e 2 (Tabela 2) que o índice de consistência mostrou uma tendência em diminuir com o aumento da temperatura. Já, para o índice de comportamento de fluxo, obteve-se o contrário, ou seja, uma tendência em aumentar (curva ascendente) com a temperatura. As amostras 1 e 2 comportaramse como fluido pseudoplástico $(\mathrm{n}<1)$, confirmando o comportamento não-Newtoniano. Todos estes comportamentos foram também verificados por Penna, Sivieri e Oliveira (2001), Lizarraga et al. (2006) e Magenis et al. (2006) em bebidas lácteas comerciais, em soluções contendo CPS e em iogurtes com ou sem a presença de retentado de soro, respectivamente.

$\mathrm{Na}$ Figura 4 tem-se a relação do efeito da temperatura e viscosidade nas amostras 1 e 2, de acordo com o modelo de Arrhenius, onde da inclinação da curva de $\ln \cdot$ versus $1 / \mathrm{RT}$, obtém-se os valores da energia de ativação de fluxo. Este modelo pôde ser perfeitamente aplicado às amostras avaliadas, pois foram encontrados coeficientes de correlação maiores do que 0,91 . Os valores para a energia de ativação foram iguais a 1,89 Kcal.mol-1 , para a amostra 1, e 1,84 Kcal.mol-1 , para a amostra 2. Estes resultados indicam que a energia de ativação não foi influenciada pelo teor de soro empregado, bem como a temperatura também não influenciou sobre a viscosidade aparente dos produtos avaliados. Valores similares $(2,02$ $\mathrm{Kcal} \mathrm{mol}^{-1}$ ) também foram determinados por AlKadamany et al. (2003) para o labneh. 


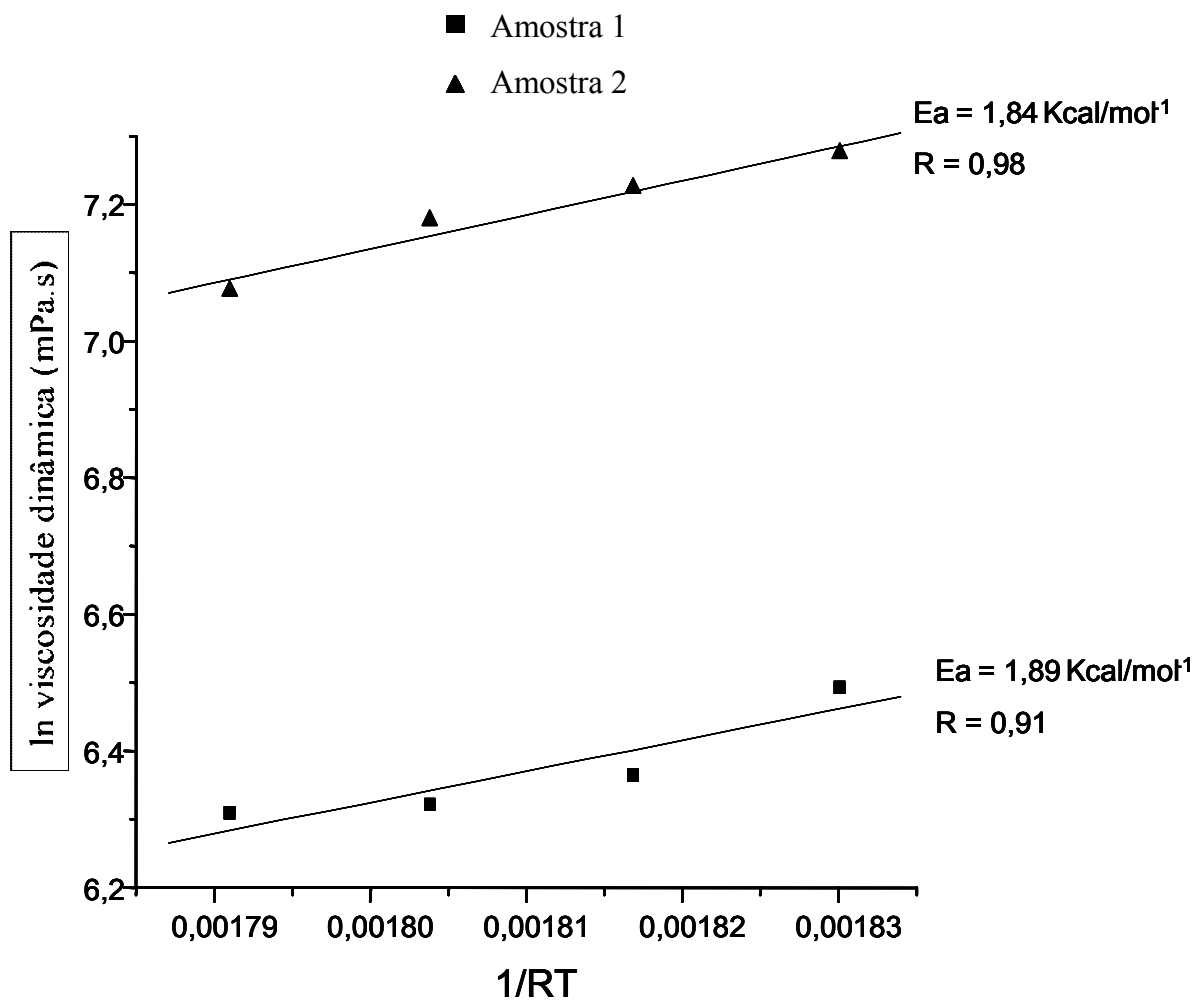

Figura 4. Efeito da temperatura na viscosidade da bebida láctea, com $70 \%$ de leite e $30 \%$ de soro (amostra 1) e leite fermentado, com $100 \%$ de leite (amostra 2).

\section{Conclusão}

A adição de soro resultou em um produto (bebida láctea) com menores teores de sólidos totais, proteínas, lipídios e valor calórico. Os teores de cinzas, carboidratos, a acidez e o $\mathrm{pH}$ da bebida láctea e do leite fermentado não diferiram entre si. Os produtos obtidos puderam ser classificados como probióticos.

Nas temperaturas e nos produtos avaliados o modelo da lei da Potência foi aplicado com sucesso para descrever as propriedades reológicas da bebida láctea e do leite fermentado. Ambos produtos comportaram-se como fluidos pseudoplásticos, confirmando o comportamento não-Newtoniano, além de apresentarem tixotropia.

A viscosidade aparente, nas temperaturas avaliadas, também diminuiu com a adição de soro de queijo. A viscosidade aparente e o índice de consistência diminuíram com o aumento da temperatura, enquanto o índice de comportamento de fluxo demonstrou uma tendência ao aumento. $\mathrm{O}$ modelo de Arrhenius foi aplicado com sucesso.

Portanto, a incorporação de soro de queijo poderia auxiliar a indústria na redução de problemas relativos ao descarte do soro, aproveitando o seu valor nutricional e funcional, bem como também gerar benefícios através da obtenção de produtos probióticos.

\section{Agradecimentos}

Nossos agradecimentos especiais pelo apoio financeiro ao PRPe/FUNPESQUISA/UFSC e à Chr. Hansen ${ }^{\circledR}$ pela doação das culturas utilizadas.

\section{Referências}

ABU-JDAYIL, B.; MOHAMEED, H. Experimental and modelling studies of the flow properties of concentrated yogurt as affected by the storage time. Journal of Food Engineering, Essex, v. 52, n. 4, p. 359-365, 2002. 
AFONSO, I. M.; HES, L.; MAIA, J. M.; MELO, L. F. Heat transfer and rheology of stirred yoghurt during cooling in plate heat exchangers. Journal of Food Engineering, Essex, v. 57, n. 2, p. 179-187, 2003.

AFONSO, I. M.; MAIA, J. M. Rheological monitoring of structure evolution and development in stirred yoghurt. Journal of Food Engineering, Essex, v. 42, n. 4, p. 183-190, 1999.

AICHINGER, P. A.; MICHEL, M.; SERVAIS, C.; DILLMANN, M. L.; ROUVET, M.; D'AMICO, N.; ZINK, R.; KLOSTERMEYER, H.; HORNE, D. S. Fermentation of a skim milk concentrate with Streptococcus thermophilus and chymosin: structure, viscoelasticity and syneresis of gels. Colloids and Surfaces B: Biointerfaces, Amsterdam, v. 31, n. 1, p. 243-255, 2003.

AL-KADAMANY, E.; KHATTAR, M.; HADDAD, T.; TOUFEILI, I. Estimation of shelf-life of concentrated yogurt by monitoring selected microbiological and physicochemical changes during storage. LWT-Food Science and Technology, London, v. 36, n. 4, p. 407-414, 2003.

ALMEIDA, K. E. de; BONASSI, I. A.; ROÇA, R. de O. Avaliação sensorial de bebida láctea preparada com diferentes teores de soro, utilizando-se dois tipos de cultura lática.. Revista do Instituto de Laticínios Cândido Tostes, v. 55, n. 315, p. 7-13, 2000.

Características físicas e químicas de bebidas lácteas fermentadas e preparadas com soro de queijo minas frescal. Ciência e Tecnologia de Alimentos, Campinas, v. 21, n. 2, p. 187-192, 2001.

ASSOCIATION OF OFFICIAL ANALYTICAL CHEMISTS - AOAC. Official methods of analysis of the association analytical chemists. 18.ed. Maryland: AOAC, 2005.

AWADHWAL, N. K.; SINGH, C. P. A Rheological model for milk products. Journal of Food Science, Chicago, v. 50, n. 6, p. 1611-1614, 1985.

AWAISHEH, S. S.; HADDADIN, M. S. Y.; ROBINSON, R. $\mathrm{K}$. Incorporation of selected nutraceuticals and probiotic bacteria into a fermented milk. International Dairy Journal, Barking, v. 15, n. 11, p. 1184-1190, 2005.

BARRETO,P.L. M.; ROEDER, J.; CRESPO, J. S.; MACIEL, G. R.; TERENZI, H.; PIRES, A. T. N.; SOLDI, V. Effect of concentration, temperature and plasticizer content on rheological properties of sodium caseinate and sodium caseinate/sorbitol solutions and glass transition of their films. Food Chemistry, London, v. 82, n. 3, p. 425-431, 2003.

BONCZAR, G.; WSZOLEK, M.; SIUTA, A. The effects of certain factors on the properties of yoghurt made from ewe's milk. Food Chemistry, London, v. 79, n. 1, p. 85-91, 2002.
DE ANGELIS, R. C. Fisiologia da nutrição: fundamentos para nutrição e desnutrição. São Paulo: EDART/EDUSP, 1977.v. 1.

DONKOR, O. N.; HENRIKSSON, A.; VASILJEVIC, T.; SHAH, N. P. Effect of acidification on the activity of probiotics in yoghurt during cold storage. International Dairy Journal, Barking, v. 16, n. 10, p. 1181-1189, 2006.

DUNNE, C.; O'MAHONY,L.; MURPHY,L.; THORNTON, G.; MORRISEY, D.; O'HALLORAN, S.; FEENEY, M.; FLYNN, S.; FITZGERALD, G.; DALY, C.; KIELY, B.; O'SULLIVAN, G. C.; SHANAHAN, F.; COLLINS, J. K. In vitro selection criteria for probiotic bacteria of human origin: correlation with in vivo findings. American Journal of Clinical Nutrition, New York, v. 73, n. 2, p. 386-392, 2001.

EL-GAWAD, I. A. A.; EL-SAYED, E. M.; HAFEZ, S. A.; ELZEINI, H. M.; SALEH, F. A. The hypocholesterolaemic effect of milk yoghurt and soy-yoghurt containing bifidobacteria in rats fed on a cholesterol-enriched diet. International Dairy Journal, Barking, v. 15, n. 1, p. 37-44, 2005.

FARIA, C. P.; BENEDET, H. D.; GUERROUE, J. L. Análise de leite de búfala fermentado por Lactobacillus casei e suplementado com Bifidobacterium longum. Semina: Ciências Agrárias, Londrina, v. 27, n. 3, p. 407-414, 2006.

FARNSWORTH, J. P.; LIA, J.; HENDRICKS, G. M.; GUO, M. R. Effects of transglutaminase treatment on functional properties and probiotic culture survivability of goat milk yogurt. Small Ruminant Research, Amsterdam, v. 65, n. 1;2, p. 113-121, 2006.

FIORAMONTI, J.; THEODOROU, V.; BUENO, L. Probiotics: what are they? What are their effects on gut physiology? Best Practice \& Research Clinical Gastroenterology, Baillière Tindall, v. 17, n. 5, p. 711-724, 2003.

FOOD AND AGRICULTURE ORGANIZATION OF THE UNITED NATIONS - FAO; WORLD HEALTH ORGANIZATION - WHO. Evaluation of health and nutritional properties of probiotics in food including powder milk with live lactic acid bacteria. Córdoba: $\mathrm{FAO} /$ WHO, 2001. Disponível em: <ftp://ftp.fao.org/docrep/fao/ meeting/009/y6398e.pdf> Acesso em: 12 mar. 2007.

GOMES, A. M. P.; MALCATA, F. X. Bifidobacterium spp. and Lactobacillus acidophilus: biochemical, technological and therapeutical properties relevant for use as probiotics. Trends in Food Science and Technology, Cambridge, v. 10, n. 4/5, p. 139-157, 1999.

GONZÁLEZ-MARTÍNEZ, C.; BECERRA, M.; CHÁFER, M.; ALBORS, A.; CAROT, J. M.; CHIRALT, A. Influence of substituting milk powder for whey powder on yogurt quality. Trends Food Science and Technology, Cambridge, v. 13, n. 9;10, p. 334-340, 2002. 
GÜLER-AKIN, M. B.; AKIN, M. S. Effects of cysteine and different incubation temperatures on the microflora, chemical composition and sensory characteristics of bioyogurt made from goat's milk. Food Chemistry, London, v. 100, n. 2, p. 788-793, 2007.

HORNE, D. S. Casein interactions: casting light on the Black Boxes, the structure in dairy products. International Dairy Journal, Barking, v. 8, n. 3, p. 171-177, 1998.

INSTITUTO ADOLFO LUTZ - IAL. Normas Analíticas do Instituto Adolfo Lutz. 4. ed. São Paulo: IAL, 2005.

KAILASAPATHY, K. Survival of free and encapsulated probiotic bacteria and their effect on the sensory properties of yoghurt. LWT- Food Science and Technology, London, v. 39, n. 10, p. 1221-1227, 2006.

KAILASAPATHY, K.; SUPRIADI, D. Effect of whey protein concentrate on the survival of Lactobacillus acidophilus in lactose hydrolyzed yoghurt during refrigerated storage. Milchwissenschaft, Munchen, v. 51, n. 10, p. 565-568, 1996.

KASTNER, S.; PERRETEN, V.; BLEULER, H.; HUGENSCHIMDT, G. ; LACROIX, C.; MEILE, L. Antibiotic susceptibility patterns and resistance genes of starter cultures and probiotic bacteria used in food. Systematic and Applied Microbiology, Stuttgart, v. 29, n. 2, p. 145155, 2006.

KEOGH, M. K.; O’ KENNEDY, B. T. Rheology of stirred yogurt as affected by added milk fat, protein and hydrocolloids. Journal of Food Science, Chicago, v. 63, n. 1, p. 108-112, 1998.

KRISTO, E.; BILIADERIS, C. G.; TZANETAKIS, N. Modelling of rheological, microbiological and acidification properties of a fermented milk product containing a probiotic strain of Lactobacillus paracasei. International Dairy Journal, Barking, v. 13, n. 7, p. 517-528, 2003.

LERAYER, A. L. S.; MIGUEL, A. M. R. de O.; GUEDES, A. L. de A.; CARVALHO, A. F. de; ITAJDENWURCEL, J. R.; FONSECA, L. M. da; MOSQUIM, M. C. A.; NUTTI, M. R.; SIMÃO FILHO, P.; BRANDÃO, S. C. C.; PORFÍRIO, T. de A. Nova legislação comentada de produtos lácteos: revisada e ampliada. São Paulo: Revista Indústria de Alimentos, 2002. v. 1.

LIN, W. H.; HWANG, C. F.; CHEN, L. W.; TSEN, H. Y. Viable counts, characteristic evaluation for commercial lactic acid bacteria products. Food Microbiology, London, v. 23, n. 1, p. 74-81, 2006.

LIZARRAGA, M. S.; DE PIANTE VICIN, D.; GONZÁLEZ, R.; RUBIOLO, A.; SANTIAGO, L. G. Rheological behaviour of whey protein concentrate and 1-carrageenan aqueous mixtures. Food Hydrocolloids, Oxford, v. 20, n. 5, p. 740-748, 2006.
LOURENS-HATTINGH, A.; VILJOEN, B. C. Yogurt as probiotic carrier food. International Dairy Journal, Barking, v. 11, n. 1-2, p. 1-17, 2001.

LUCEY, J. A. Formation and physical properties of milk protein gels. Journal of Dairy Science, Champaign, v. 85, n. 2, p. 281-294, 2002.

LUCEY, J. A.; MUNRO, P. A.; SINGH, H. Effects of heat treatment and whey protein addition on the rheological properties and structure of acid skim milk gels. International Dairy Journal, Barking, v. 9, n. 3, p. 275 279, 1999.

LUCEY, J. A.; SINGH, H. Formation and physical properties of acid milk gels: a review. Food Research International, Barking, v. 30, n. 7, p. 529-542, 1998.

MAGENIS, R. B.; PRUDÊNCIO, E. S.; AMBONI, R. D. M. C.; CERQUEIRA JÚNIOR, N. G.; OLIVEIRA, R. V. B.; SOLDI, V.; BENEDET, H. D. Compositional and physical properties of yogurts manufactured from milk and whey cheese concentrated by ultrafiltration. International Journal of Food Science and Technology, Oxford, v. 41, n. 5, p. 560-568, 2006.

MARAGKOUDAKIS, P. A.; MIARIS, C.; ROJEZ, P.; MANALIS, N.; MAGKANARI, F. KALANTZOPOULOS, G.; TSAKALIDOU, E. Production of traditional Greek yoghurt using Lactobacillus strains with probiotic potential as starter adjuncts. International Dairy Journal, Barking, v. 16, n. 1, p. 52-60. 2006.

MARTÍN-DIANA, A. B.; JANER, C.; PELÁEZ, C. REQUENA, T. Development of a fermented goat's milk containing probiotic bacteria. International Dairy Journal, Barking, v. 13, n. 10, p. 827-833, 2003.

MARTÍNEZ-VILLALUENGA, C.; FRÍAS, J.; GÓMEZ, R.; VIDAL-VALVERDE, C. Influence of addition of raffinose family oligosaccharides on probiotic survival in fermented milk during refrigerated storage. International Dairy Journal, Barking, v. 16, n. 7, p. 768-774, 2006.

MOREIRA, M.; ABRAHAM, A.; DE ANTONI, G. Technological properties of milks fermented with thermophilic lactic acid bacteria at suboptimal temperature. Journal of Dairy Science, Champaign, v. 83, n. 3, p. 395 400, 2000.

MOREIRA, S. R.; SCHWAN, R. F.; CARVALHO, E. P.; FERREIRA, C. Análise microbiológica e química de iogurtes comercializados em Lavras-MG. Ciência e Tecnologia de Alimentos, Campinas, v. 19, n. 1, p. 147152, 1999.

MULLINEUX, G.; SIMMONS, M. J. H. Effects of processing on shear rate of yoghurt. Journal of Food Engineering, Essex, v. 79, n. 3, p. 850-857, 2007. 
MUSAIGER, A. O.; AL-SAAD, J. A.; AL-HOOTI, D. S.; KHUNJI, Z. A. Chemical composition of fermented dairy products consumed in Bahrain. Food Chemistry, London, v. 61, n. $1 / 2$, p. $49-52,1998$.

O’DONNELL, H. J.; BUTLER, F. Time-dependent viscosity of stirred yogurt. Part II: tube flow. Journal of Food Engineering, Essex, v. 51, n. 3, p. 255-261, 2002.

OLIVEIRA, M. N.; DAMIN, M. R. Efeito do teor de sólidos e da concentração de sacarose na acidificação, firmeza e viabilidade de bactérias do iogurte e probióticas em leite fermentado. Ciência e Tecnologia de Alimentos, Campinas, v. 23, n. 1, p. 172-176, 2003.

PENNA, A. L. B.; SIVIERI, K.; OLIVEIRA, M. N. Relation between quality and rheological properties of lactic beverages. Journal of Food Engineering, Essex, v. 49, n. 1, p. 7-13, 2001.

PINTADO, M. E.; MACEDO, A. C.; MALEATA, F. X. Review: technology, chemistry and microbiology of whey cheeses. Food Science Technology International, London, n. 7, n. 2, p. 105-116, 2001.

PINTO, M. G. V.; FRANZ, C. M. A. P.; SCHILLINGER, U.; HOLZAPFEL, W. H. Lactobacillus spp. with in vitro probiotic properties from human faeces and traditional fermented products. International Journal of Food Microbiology, Amsterdam, v. 109, n. 3, p. 205-214, 2006.

RODRIGUES, L. R.; TEIXEIRA, J. A.; OLIVEIRA, R. Lowcost fermentative medium for biosurfactant production by probiotic bacteria. Biochemical Engineering Journal, Amsterdam, n. 32, n. 3, p. 135-142, 2006.

SCHRAMM, G. Reologia e reometria: fundamentos teóricos e práticos. São Paulo: Artliber, 2006.

SHAH, N. P. Probiotic bacteria: selective enumeration and survival in dairy foods. Journal of Dairy Science, Champaign, v. 83, n. 4, p. 894-907, 2000.

SHAKER, R. R.; JUMAH, R. Y.; ABU-JDAYIL, B. Rheological properties of plain yogurt during coagulation process: impact of fat content and preheat treatment of milk. Journal of Food Engineering, Essex, v. 44, n. 3, p. 175-180, 2000.

SHOEMAKER, C. F.; FIGONI, P. A.; Time-dependent rheological behavior of foods. Food Technology, Chicago, v. 38,p. 110-112, 1984.

SILVA, F. C.; GUIMARÃES, D. H. P.; GASPARETTO, C. A. Reologia do suco de acerola: efeitos da concentração e temperatura. Ciência e Tecnologia de Alimentos, Campinas, v. 25, n. 1, p. 121-126, 2005.
SINHA, R.; RADHA, C.; PRAKASH, J.; KAUL, P. Whey protein hydrolysate: Functional properties, nutritional quality and utilization in beverage formulation. Food Chemistry, London, v. 101, n. 4, p. 1484-1491, 2007.

SISO, M. I. G. The biotechnological utilization of cheese whey: a review. Bioresource Technology, Essex, v. 57, n. 1,p. 1-11, 1996.

SODINI, I.; LUCAS, A.; TISSIER, J. P.; CORRIEU, G. Physical properties and microstructure of yoghurts supplemented with milk protein hydrolysates. International Dairy Journal, Barking, v. 15, n. 1, p. 29-35, 2005.

STATSOFT INC. Statistica data analysis system version 6.0. Tulsa: Statsoft Inc., 2001.

TEO, C. T.; MUNRO, P. A.; SINGH, H. Time dependence of rheological breakdown and recovery of heat precipitated whey protein suspensions. Milchwissenschaft, Munchen, v. 55, p. 29-32, 2000.

THAMER, K. G.; PENNA, A. L. B. Efeito do teor de soro, açúcar e de frutooligossacarídeos sobre a população de bactérias láticas probióticas em bebidas fermentadas. Revista Brasileira de Ciências Farmacêuticas, São Paulo, v. 41, n. 3, p. 393-400, 2005.

VELEZ-RUIZ, J. F.; BARBOSA-CANOVAS, G. V. Rheological properties of concentrated milk as a function of concentration, temperature and storage time. Journal of Food Engineering, Essex, v. 35, n. 2, p. 177-190, 1998.

VINDEROLA, C. G.; BAILO, N.; REINHEIMER, J. A. Survival of probiotic microflora in Argentinian yoghurts during refrigerated storage. Food Research International, Barking, v. 33, n. 2, p. 97-102, 2000.

VINDEROLA, C. G.; REINHEIMER, J. A. Enumeration of Lactobacillus casei in the presence of L. acidophilus, bifdobacteria and lactic starter bacteria in fermented dairy products. International Dairy Journal, Barking, v. 10, $\mathrm{n}$. 4, p. 271-275, 2000.

YANES, M.; DURÁN, L.; COSTELL, E. Effect of hydrocolloid type and concentration on flow behaviour and sensory properties of milk beverages model systems. Food Hydrocolloids, Oxford, v. 16, n. 6, p. 605-611, 2002.

YAZICI, F.; AKGUN, A. Effect of some protein based fat replacers on physical, chemical, textural, and sensory properties of strained yoghurt. Journal of Food Engineering, Essex, v. 62, n. 3, p. 245-254, 2004. 